\title{
Erratum to: Atmospheric deposition of heavy metals in the mining area of the San Jorge river basin, Colombia
}

\author{
José Luis Marrugo-Negrete • Ivan D. Urango-Cardenas • \\ Saudith M. Burgos Núñez • Sergi Díez
}

Published online: 19 August 2014

(C) Springer Science+Business Media Dordrecht 2014

Erratum to: Air Qual Atmos Health

DOI 10.1007/s11869-014-0260-0

Figure 4 map image scales were incorrect in the original version of the paper. Figure 4 has now been reproduced correctly and can be seen below. The publisher apologizes for any inconvenience and is pleased to rectify the mistake here.

The online version of the original article can be found at http://dx.doi.org/ 10.1007/s11869-014-0260-0.

J. L. Marrugo-Negrete • I. D. Urango-Cardenas · S. M. B. Núñez Water, Applied and Environmental Chemistry Group, University of Córdoba, Montería, Colombia

S. Díez

Environmental Chemistry Department, Institute of Environmental Assessment and Water Research, IDÆA-CSIC, 08034 Barcelona, Spain

I. D. Urango-Cardenas ( $\triangle)$

Laboratory Toxicology and Environmental Management, University of Córdoba, Cra 6 \# 76-103, Montería, Colombia

e-mail: ivaild@hotmail.com 
a

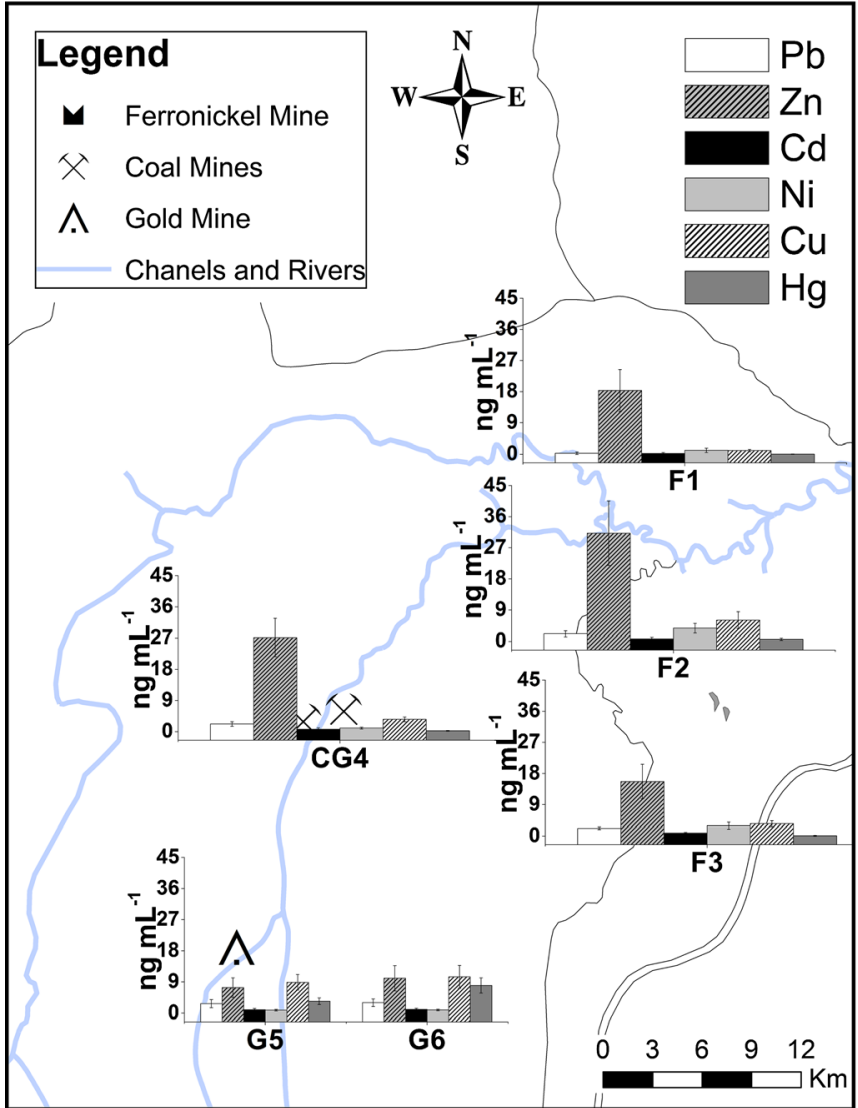

b

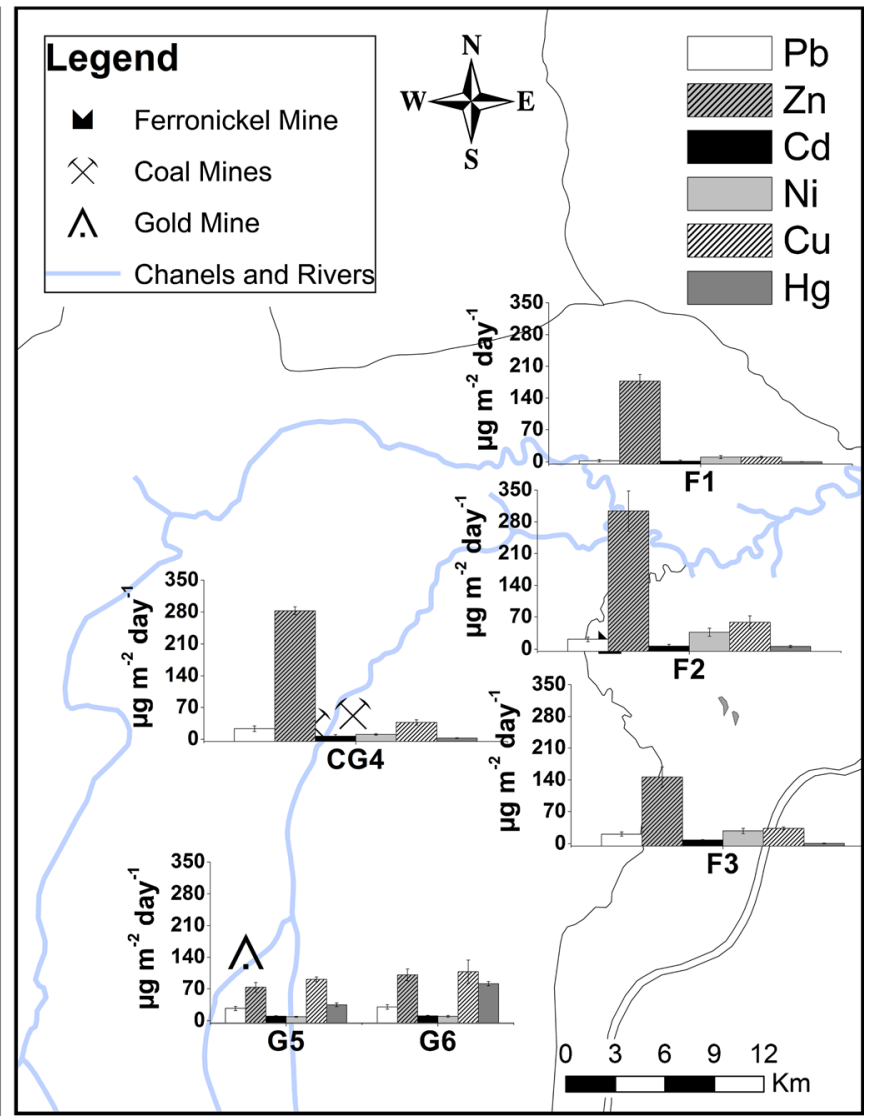

